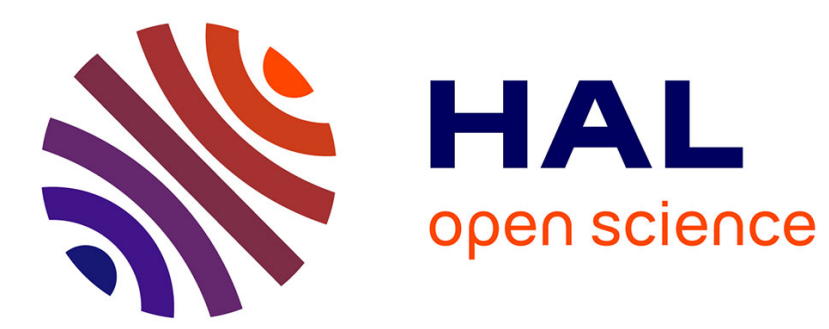

\title{
TRANSIENT REGIMES OF HOT CARRIERS IN p-TYPE SILICON
}

\author{
L. Reggiani, J.-C. Vaissière, J.-P. Nougier, D. Gasquet
}

\section{To cite this version:}

L. Reggiani, J.-C. Vaissière, J.-P. Nougier, D. Gasquet. TRANSIENT REGIMES OF HOT CARRIERS IN p-TYPE SILICON. Journal de Physique Colloques, 1981, 42 (C7), pp.C7-357-C7-367. 10.1051/jphyscol:1981744 . jpa-00221681

\section{HAL Id: jpa-00221681 https://hal.science/jpa-00221681}

Submitted on 1 Jan 1981

HAL is a multi-disciplinary open access archive for the deposit and dissemination of scientific research documents, whether they are published or not. The documents may come from teaching and research institutions in France or abroad, or from public or private research centers.
L'archive ouverte pluridisciplinaire HAL, est destinée au dépôt et à la diffusion de documents scientifiques de niveau recherche, publiés ou non, émanant des établissements d'enseignement et de recherche français ou étrangers, des laboratoires publics ou privés. 


\title{
TRANSIENT REGIMES OF HOT CARRIERS IN P-TYPE SILICON
}

\author{
L. Reggiani, J.C. Vaissière, J.P. Nougier ${ }^{*}$ and D. Gasquet \\ Gruppo Nazionale di Struttura delza Matemia, Istituto di Fisica, Università di \\ Modena, Via Compi 213/A, 41100 Modena, Italy \\ * Université des Sciences et Techniques du Languedoc, Centre d'Etudes d'Electro- \\ nique des Solides, Laboratoire associé au C.N.R.S. LA 21 et Greco Microondes, \\ 34060 Montpelitier Cedex, Fronce
}

Résumé : On compare les rêgimes transitoires obtenus, sur si-p à $300 \mathrm{~K}$, par simuTation de Monte Carlo et résolution itérative de l'équation de Boltzmann: l'accord est excellent. Le régime transitoire : a) dépend assez peu des formes de bandes d'énergie. b) dépend beaucoup de 7 'énergie initiale, une augmentation de celle-ci peut faire disparaitre la survitesse. c) dépend peu de la forme de la distribution initiale. Dans tous les cas, le régime transitoire déterminé en utilisant les équations dynamiques donne un accord très satisfaisant avec les précédentes simulations.

Abstract : A comparison is made between transient regimes obtained, on $\mathrm{p}-\mathrm{Si}$ at $300 \mathrm{~K}$, by a Monte Carlo simulation and by an iterative solution of the Boltzmann equation : the agreement is excellent. The transient regime : a) depends relatively few on the energy bandshapes; b) Is strongly dependent on the initial energy, the increase of which may lead to a disappearance of the velocity overshoot; c) Slowly depends on the shape of the initial distribution function. In every cases, the transient regime computed using the balance equations is in very satisfactory agreement with the previous simulations.

\section{INTROOUCTION}

For studying transient regimes in homogeneous semiconductors, three methods can be used. i) iterative technique, ii) Monte Carlo simulation, iii) balance equations. Within the frame of the classical Boltzmann equation, the first two methods are exact numerical solutions $\left(\left[\begin{array}{ll}1 & -6\end{array}\right]\right)$. However, no direct comparison of the transient regime obtained by both methods have been performed tili now. In this paper, various transient regimes are compared for the case of holes in si using both methods with the same band structure and the same scattering mechanisms in order to check their reliability on a practical case of interest. Transient regimes corresponding to various initial conditions are studied. The influence of valence band particularities (such as nonparabolicity and warping) are investigated. Furthermore, comparison of these methods with the balance equations is carried out with the aim to provide a reference for estimating differences between realistic and simplified models used in practical calculations. 
After a brief recall of the methods used (section 2), we shall compare (section 3 ) the various models, then study the influences of the dispersion relation $\varepsilon(\vec{k})$ (section 4), of the initial energy distribution (section 5), and of the initial distribution function (section 6), before giving an example showing an undershoot velocity. (section 8$)$.

\section{METHODS USED}

The values of the transport quantities of interest for a transport dynamic response can be obtained from a Monte Carlo procedure by simulating the behaviour of a number of independent particles and taking ensemble averages over the whole gas, at given values of time $t[7]$. For our case, 8192 particles have been considered and the space distribution has been assumed to be of a Dirac type; different initial energy distributions with different mean values have been considered, as will be discussed in the following. As in the stationary case, the self scattering mechanism has been included in the simulation. Of course, the results have been found to be independent from the choice of the self-scattering parameter $\Gamma$, contrary to what stated in refs. [8][9], provided that $\Gamma$ is large enough.

The iterative method used for solving the Boltzmann equation was described in ref. [10], and has been extended here to the case of a two bands semiconductor.

The method of balanced equations was recently shown [11] to be a good approximation deduced from the Boltzmann equation. Its application proved to be successful [11] [ 12] in $n-S i, p-G e$ and $n$-GaAs.

\section{COMPARIS,ON BETWEEN THE MODELS}

In order to compare the Monte Carlo and iterative solutions on the same microscopic model, and to avoid two much time consuming computations, we used a simplified band structure model consisting in a single spherical band with an effective mass which, to account for nonparabolic effects, has been taken to be dependent upon the electric field strength through the stationary value of the hole mean energy. Acoustic scattering, which accounts for overlap effects, and non-polar optical scattering, have been considered. The values used in calculations are reported in Table 1, and Fig. 1 shows the dependence of the effective mass with the electric fieldstrengh. The reliability of the microscopic model, which differs from that of Ref. [13] only for warping effects, is checked with the comparison of theoretical and experimental results of the stationary values of the drift velocity and longitudinal diffusion coefficient $[14]$, as shown in Fig. 2. The overlapp was taken into account by setting $G\left(\vec{k}, \vec{k}^{\prime}\right)=1 / 2$, thus having the effect of deviding by 2 the value of $E_{1}^{0}$ given in table 1.

The initial distribution function was assumed to be the thermal equilibrium Maxwell Boltzmann distribution at $300 \mathrm{~K}$. 


\begin{tabular}{|c|c|c|c|c|}
\hline \multirow[b]{2}{*}{ Quantity } & \multirow[b]{2}{*}{ Unit } & \multicolumn{3}{|c|}{$V$ a $T$ u e } \\
\hline & & $\begin{array}{l}\text { One spherical } \\
\text { parabolic band }\end{array}$ & $\begin{array}{l}\text { Two spherical } \\
\text { parabolic bands }\end{array}$ & $\begin{array}{l}\text { Two spherical } \\
\text { bands: one para- } \\
\text { bolic and one } \\
\text { non parabolic }\end{array}$ \\
\hline$\rho \quad[15]$ & $\mathrm{gr} / \mathrm{cm}^{3}$ & 2.33 & 2.33 & 2.33 \\
\hline$\theta \quad[15]$ & K & 735 & 735 & 735 \\
\hline $\mathrm{s}_{\mathrm{e}}[15]$ & $\mathrm{cm} / \mathrm{s}$ & $9.04 \times 10^{5}$ & $9.04 \times 10^{5}$ & $9.04 \times 10^{5}$ \\
\hline $\mathrm{s}_{\mathrm{t}}^{\mathrm{c}} \quad[15]$ & $\mathrm{cm} / \mathrm{s}$ & $5.34 \times 10^{5}$ & $5.34 \times 10^{5}$ & $5.34 \times 10^{5}$ \\
\hline $\mathrm{m}_{10} / \mathrm{m}_{0}[15]$ & - & - & - & $0.50 \quad[16]$ \\
\hline $\mathrm{m}_{11} / \mathrm{m}_{0}[15]$ & - & - & - & 1.16 \\
\hline$m_{h} / m_{0}$ & - & $\mathrm{m}(\mathrm{E}) / \mathrm{m}_{0}[$ see $\mathrm{Fig} .1]$ & 1.16 \} (see Fig.3 & - \\
\hline$m_{\ell} / m_{0}$ & - & - & $0.30\}$ of $[16])$ & {$[16]$} \\
\hline $\mathrm{E}_{1}^{\circ} \quad[13]$ & $\mathrm{eV}$ & 5.0 & 5.0 & 5.0 \\
\hline [13] & $\mathrm{eV}$ & 26.6 & 26.6 & 26.6 \\
\hline
\end{tabular}

Table 1. Constants used in the calculations for the various band models used in the present paper. The notations are the usual ones and the quantities are defined, or given in the references 1 isted. The non parabolic band consists in two parabolic portions of masses $m_{10}$ and $m_{11}$,
linked by a linear portion [15].

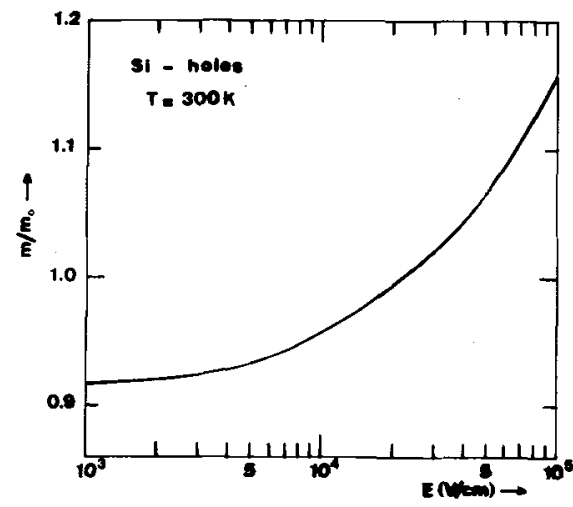

Fig. 1 : Equivalent effective mass as a function of the electric field for the one band model, see Ref. [15].

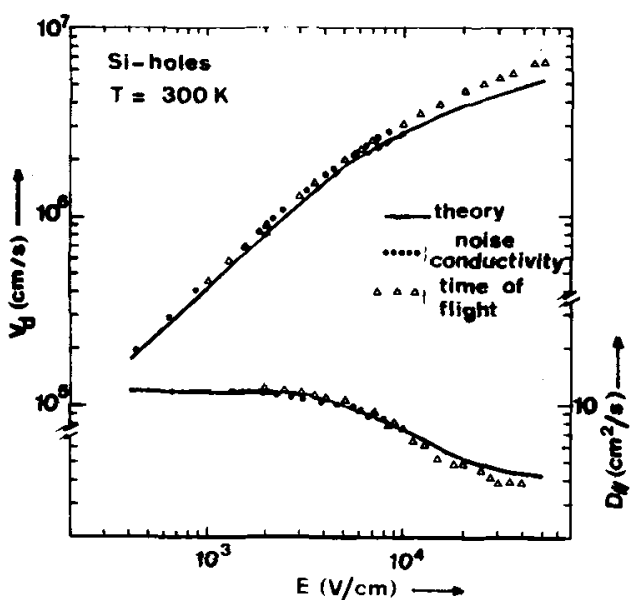

Fig. 2 : Comparison between the experimental results, of drift velocity and diffusion, and the theory using the one band mode' (taken from [14]). 
Figures $3 a$ and $3 b$ show the transient drift velocity and the transient energy for a set of electric fields suddenly applied at $t=0\left(E=10,20\right.$ and $\left.50 \mathrm{kV} \mathrm{cm}^{-1}\right)$. The values obtained with the Monte Carlo (circles, triangles and stars) and the iterative method (dotted curves) are found to coincide within the statistical uncertainty. This evidence proves the complete reliability of both methods to solve the Boltzmann equation under transient conditions. In particular, drift velocity is found to exhibit overshoot for field strengths above about $20 \mathrm{kV} / \mathrm{cm}$. No overshoot was found for the energy.

On figure 3 are also plotted the transient regimes computed using the balance equations : these results are in agreement within $10 \%$ with the "exact" ones, which is much satisfactory if one takes into account the great simplicity and rapidity of this method. These results are similar to those previously obtained [11] [12] on $p-G e, n-S i$ and $n-G a A s$.
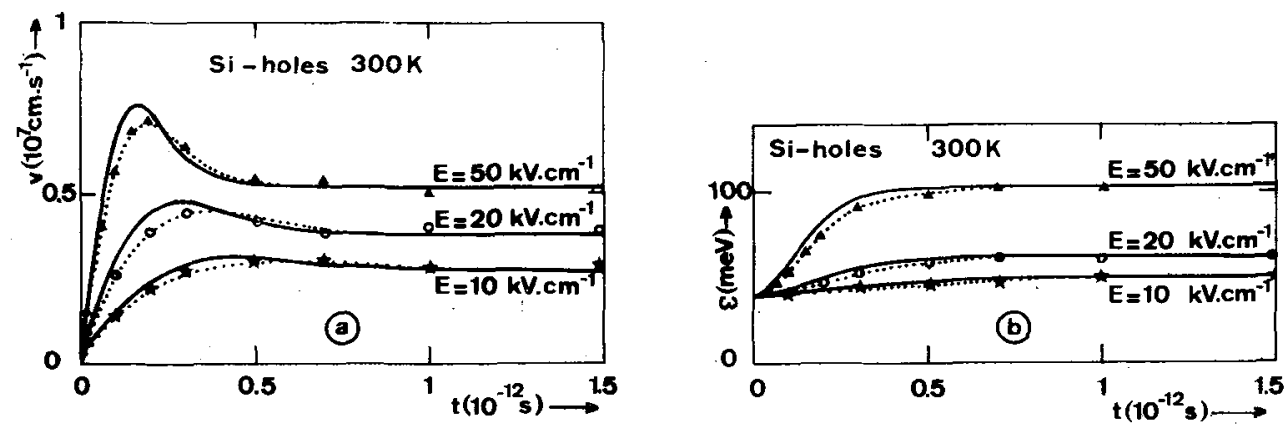

Fig. 3 : Transient drift velocities (a) and energies (b) in p-Si at $300 \mathrm{~K}$, for various values of suddenly applied electric fields at $t=0$. Comparison between : iterative solution of the Boltzmann equation (dotted curves), Monte Carlo simulation (circles, triangles and stars), and balance equations (futl curves).

\section{INFLUENCE OF THE BANDSHAPES ON THE TRANSIENT REGIMES :}

During the transient regimes, the "average position" of the carriers in the $|\vec{k}|$ space vary, so as their "average mass". Therefore, one could expect that for various bandshapes the transient motion is not the same. This is shown on Fig. 4 where the transient drift velocity is plotted for an electric field step of $E=50$ $\mathrm{kV} \mathrm{cm}{ }^{-1}$, applied at $t=0$, and for various dispersion laws $\varepsilon(k)$. The following models have been used, their parameters are listed table 1 :

(i) One spherical parabolic band described in the previous section

(ii) Two spherical parabolic bands with effective masses $m_{h}$ and $m_{e}$

(iii) Two spherical bands, a light hole band parabolic and the heavy hole band non 
parabolic consisting in two parabolic portions, of effective masses $m_{10}$ and $\mathrm{m}_{11}$, linked by a linear portion $[15]$.

(iv) One warped sphere band described in [13].

of course onty the warped sphere model is able to exhibit anisotropy. As is shown on Fig. 4, the drift velocity (and so is the mean energy) is higher along a $<100\rangle$ direction than along a $<111>$ direction. This reflects the lower value of the heavy hole effective mass along this direction. In particular, it has to be noted that the anisotropy exhibited by the drift velocity reaches it maximum value around the peak of the overshoot where, for the field strength considered, variations of about $30 \%$ have been found.

Fig. 4 clearly shows that different bandshapes give different transient drift velocities, even when the steady state velocities are equal.

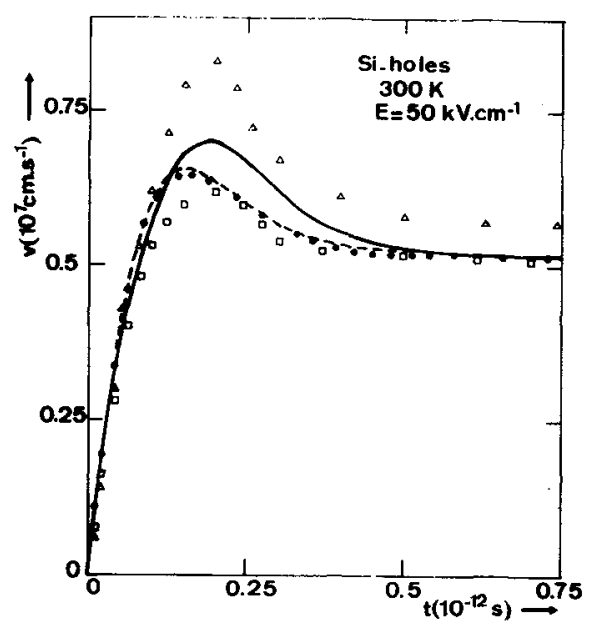

Figure 4 : Transient velocities for different bandshapes : warped spheres, $E / /<100>(\Delta)$ and $E / /<111>$ ( $\mathbf{0})$; two spherical bands, one parabolic and one non parabolic (e) ; two spherical parabolic bands $(-\rightarrow)$; one spherical parabolic band (-).

\section{EFFECT OF THE INITIAL ENERGY}

In order to investigate the effect of the initial. energy on the transient behaviour, an electric field step of $50 \mathrm{kV} / \mathrm{cm}$ was applied at $\mathrm{t}=0$ to $\mathrm{p}-\mathrm{Si}$ at $300 \mathrm{~K}$ with the one spherical parabolic band model discussed above, corresponding to three different initial conditions described by the following distribution functions $f_{0}(\vec{k})$ ( $\delta$ is the Dirac function) :

conditions 1 : $f_{0}(\vec{k}) \propto \delta(0)$ : all the carriers are initially located at $\vec{k}=0$, thus $\bar{v}(0)=0$ and $\bar{\varepsilon}(0)=0$.

conditions 2: $f_{0}(\vec{k}) \propto \delta\left(k_{0}\right)$ where $\varepsilon\left(k_{0}\right)=0.75 \mathrm{eV}:$ all the carriers have the initial energy $0.75 \mathrm{eV}$, but their velocities are randomly distributed $: \bar{v}(0)=0$ and $\bar{\varepsilon}(0)=0.75 \mathrm{ev} \cdot[17]$ 
conditions $3: f_{0}(\vec{k})=$ thermal equilibrium distribution at $300 \mathrm{~K}: \bar{v}(0)=0$ and $\bar{\varepsilon}(0)=0.039 \mathrm{eV}$.

of course the condition number 1 is unrealistic (the case number 2 could describe carriers injected using an electron gunn), but these three cases are interesting for testing the reliability of the methods since they represent very extreme conditions.

Figure $5 \mathrm{a}$ and $5 \mathrm{~b}$ show the results obtained on the transient velocity and energy using the three techniques of simulation (Monte Carlo, iterative, balance equations). As can be seen on.Fig. 5a, the overshoot is maximum with the condition 1 , while it disappears for the condition 2. In fact, in the former case the carriers start to accelerate before to dissipate energy and, provided that the field strength is high enough, as it is in this case, due to the streaming effect of the field they have the possibility to reach velocity values higher than the stationary one. In the case number 2 the carriers simultaneously start to accelerate and dissipate energy through phonon emission; this process is quite randomizing in momentum and leads to a smoth increase with time of the drift velocity, so that overshoot effects disappear. Thus the influence of the initial energy and distribution is quite important on the transient velocity. The slight discrepancy appearing between the Monte Carlo and iterative simulations comes to the fact that, with our iterative technique, discontinuities are forbidden, so that we are unable to simulate delta functions : these were then replaced by narrow Gaussian distributions, which tends to lower the overshoot in the case number 1 . As concerning the transient energies (see Fig. 5b), no overshoot is observed. Finally it can be remarked, on Fig. 5a, that the slopes of $v(t)$ at the origin are identical : this is quite normal, and eq. (16) of reference $[11]$ shows that, without any approximation: when $v(t=0)=0$ : $(d v / d t)_{t=0}=e E / m$ and thus does not depend on the initial distribution provided that $v(t=0)=0$. However, as can be seen from eq. (24) of ref. [11], (d $\varepsilon / d t)_{t=0}$ depends on $\varepsilon(t=0)$ even when $v(t=0)=0$, as is obviously confirmed by Fig. 5b.

Finally one should note that the balance equations give transient curves in quite good agreement with the exact methods. 

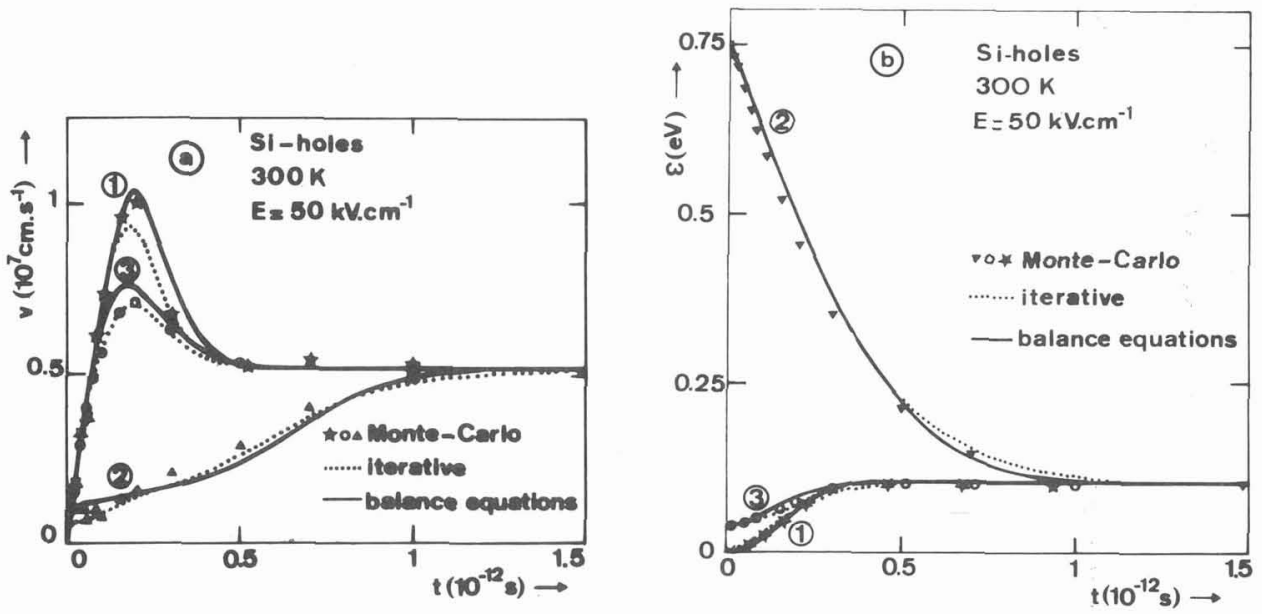

Fig. 5 : Transient velocities (a) and energies (b) computed using the three techniques of simulation: (Monte Carlo ( ), iterative $(\cdots \cdots)$, and balance eqs. ( -$)$ ), for various initial conditions : (1): $f_{0}(k) \propto \delta(0)$; (2) $: f_{0}(k) \propto \delta\left(k_{0}\right)$ where $\varepsilon\left(k_{0}\right)=0.75 \mathrm{eV}$; (3) : $f_{0}(k)=$ thermal equilibrium distribution at $300 \mathrm{k}$.

\section{INFLUENCE OF THE INITIAL DISTRIBUTION FUNCTION}

The balance equations do not take into account the distribution function, they describe only the notion of the average velocity and of the average energy. In order to get an idea of the error performed by neglecting the shape of the distribution function, we study the transient velocities (Fig. 6a) and energies (Fig. 6b) for a step of electric field $E=50 \mathrm{kV} / \mathrm{cm}$ applied at $t=0$, the carriers being, at $t=0$, distributed according to the two following laws giving both $\bar{v}(0)=0$ and $\vec{\varepsilon}(0)=0.5 \mathrm{eV}:$ 1) $f_{0}(\vec{k}) \propto \exp \left(-\hbar^{2} k^{2} / 2 \mathrm{~m} \mathrm{k}_{B} \mathrm{~T}_{0}\right)$ with $3 k_{B} T_{0} / 2=0.5 \mathrm{eV}$ (thermal equilibrium at $T_{0}=3870 \mathrm{~K}$ ). This condition is of course unrealistic, but corresponds to a limiting case where all the energies in the $\{\vec{k}\}$ space are occupied. 2) $f_{0}(\vec{k}) \propto \exp \left[-\hbar^{2}\left(k-k_{1}\right)^{2} / 2 m k_{B} T_{1}\right]$ with $k_{1}$ such that $\hbar^{2} k^{2}{ }_{1} / 2 m=0.5$ ev and $\mathrm{T}_{1}=40 \mathrm{~K}$. This corresponds to carriers located in a narrow region of $\pm 5.2 \mathrm{meV}$ around the energy $0.5 \mathrm{eV}$.

The transient responses were computed using the iterative method, for the single spherical parabolic band model. Fig. $6 a$ and $6 \mathrm{~b}$ show that the discrepancy between the two transient responses is not very large. As a consequence, the description given by the balance equations is, in this case two, quite satisfactory as shown in Fig. 6. 

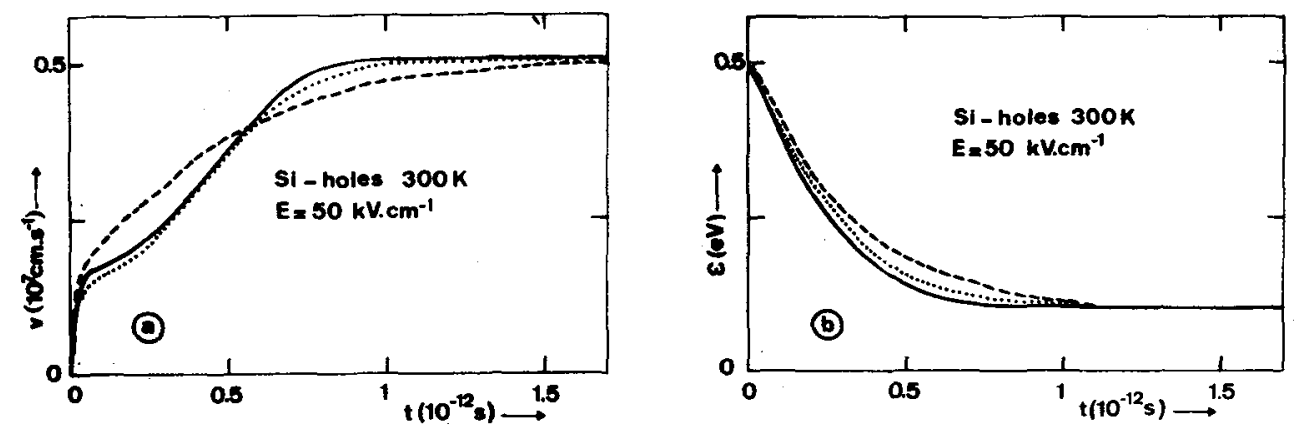

Figure 6 : Transient drift velocities (a) and energies (b) for $\mathrm{p}-\mathrm{Si}, 300 \mathrm{~K}$, in a step of $E=50 \mathrm{kV} / \mathrm{cm}$, for two initial distributions $v(0)=0$ and $\varepsilon(0)=0.5 \mathrm{eV}$; $(\ldots$.$) all the carriers have an energy equal to 500 \pm 5.2 \mathrm{meV}$, and the directions of the $\vec{k}$ vector are randomily distributed, iterative method ;(- - -) maxwillian distribution centered at $k=0$, with average energy $0.5 \mathrm{eV}$, iterative method; (-) balance equations.

\section{EXAMPLE : UNDERSHOOT VELOCITY :}

Let us apply at time $t=0$, a constant electric field $E_{1}$ : after an overshoot (if $E_{1} \geqslant 20 \mathrm{kV} \mathrm{cm}^{-1}$ ), the velocity reaches its stationary value. If then, at time $t_{1}$, the field is suddenly lowered and takes the constant value $E_{2}$, the velocity may exhibit an undershoot value before stabilizing at the steady state corresponding to the field $E_{2}$. This phenomenon is shown on figure $7 a$ and $7 b$ where $E_{2}$ was taken equal to $10 \mathrm{kV} \mathrm{cm}{ }^{-1}$, starting at time $t_{1}=1.5 \mathrm{ps}$. The simulation was performed using three values of $E_{1}\left(20,50\right.$ and $\left.100 \mathrm{kV} \cdot \mathrm{cm}^{-1}\right)$ with the balance equations (respectively dotted, dashed and full curves of figures $7 \mathrm{a}$ and $7 \mathrm{~b}$ ). It was checked at $50 \mathrm{kV} \mathrm{cm}-1$ by comparing the result obtained, with the iterative solution of the Boltzmann equation for the one parabolic band model, the system being at $t<0$ in thermal equilibrium : the agreement between the iterative method and the balance equation is excellent. The drift velocity, shown in Fig. 7a, exhibits an overshoot at the increase of electric field. An undershoot appears at the decrease of electric field, the more pronounced as the intermediate field $E_{1}$ is higher. Figure $7 b$ shows that no overshoot nor undershoot are observed on the average energy. For both the energy and (even more) the velocity, the transient regime is almost twice longer for the decrease of the electric field than for the increase. The velocity undershoot had already been predicted on multivalley semiconductors ( $n-S i$ and $n$ GaAs [ 12$]$ ). However it is shown here to be possible even with a single band structure.

When the electric field is suppressed instead of being lowered $\left(E_{2}=0\right)$, the velocity remains positive, but the decay time decreases with increasing $E_{1}$. 

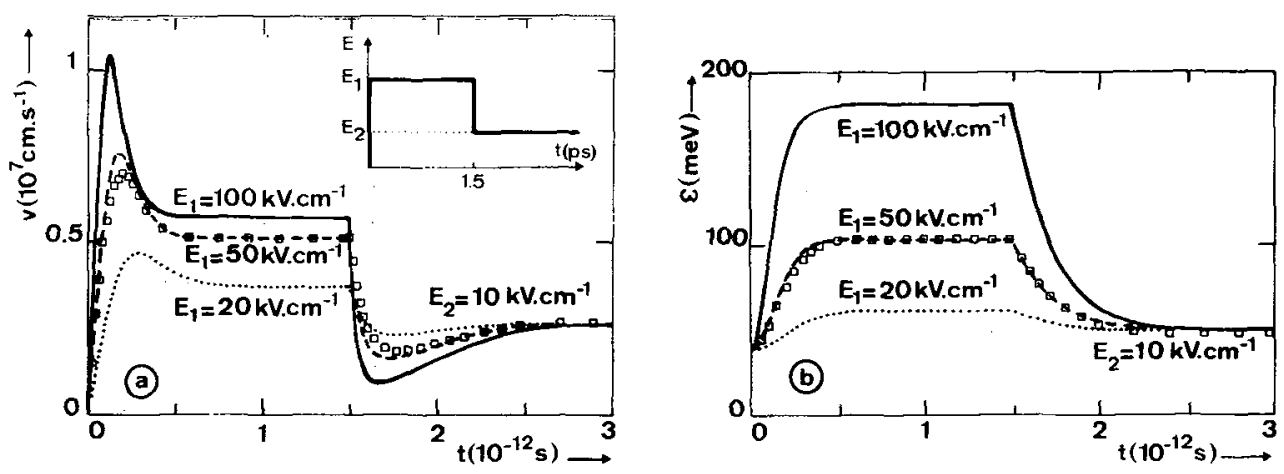

Figure 7 : Transient velocity (a) and energy (b) responses to an electric field $E_{1}$ applied at $t=0$ and $E_{2}$ applied at $t=t_{1} \cdot t_{1}=1.5 \mathrm{ps}, E_{2}=10 \mathrm{kV} \mathrm{cm}-1$. The iterative method $(a)$ was applied for $E_{1}=50 \mathrm{kV} \mathrm{cm}^{-1}$, and the balance equations were used for $E_{1}=20 \mathrm{kV} \mathrm{cm}^{-1}(\ldots), E_{1}=50 \mathrm{kV} \mathrm{cm}^{-1}(--)$ and $E_{1}=100 \mathrm{kV} \mathrm{cm}^{-1}(\rightarrow)$.

8. CONCLUSION

Transient regime of hot holes in Si has been studied using three different methods. Iterative technique and Monte Carlo simulation have been proved to produce the same results when the microscopic model is kept to be the same. Due to the lack of experimental data, the present investigation has been devoted to analyze systematically some physical situations in order to offer plausible expectations on transient regime effects. So, overshoot of the drift velocity has been found to be magnified by lowering the initial carrier energy and, by considering warping, when the field is oriented along $\langle 100\rangle$ direction.

The transient regimes were found to depend strongly on the initial average velocities and energies : diminishing the initial energy enhances the velocity overshoot. However, the transient regime depends very few on various initial distributions corresponding to the same initial average velocity and energy.

In every case, in spite of the great variety of conditions studied, the balance equations gave results in quite satisfactory agreement with iterative or Monte Carlo methods. This strongly justifies the use of the balance equations, which is a very fast and cheap method.

of course the steady state regime is completely independent from the initial conditions. On the basis of these new results and of our experience with the three methods discussed above, we have drawn a general syntetic overview on the advantages and limitations of each method, which is reported in tables 2 and 3 . 


\begin{tabular}{|c|c|c|}
\hline Balance equations & Iterative technique & Monte Carlo simulation \\
\hline \multirow[t]{3}{*}{$\begin{array}{l}\text { Simple and fast method. } \\
\text { A desk computer is suf- } \\
\text { ficient. }\end{array}$} & \multicolumn{2}{|c|}{$\begin{array}{c}\text { An exact solution of the Boltzmann equation is } \\
\text { obtained }\end{array}$} \\
\hline & $\begin{array}{l}\text { The carrier distribution } \\
\text { function is obtained with } \\
\text { great detail and in a very } \\
\text { direct way }\end{array}$ & $\begin{array}{l}\text { The microscopic dynamics } \\
\text { is quite transparentsin } \\
\text { ce each scattering pro- } \\
\text { cess can be analized in } \\
\text { full detail. }\end{array}$ \\
\hline & \multicolumn{2}{|c|}{$\begin{array}{l}\text { Different initial conditions and initial distribu- } \\
\text { tion functions can be simulated in a rather simple } \\
\text { way. }\end{array}$} \\
\hline \multirow[t]{2}{*}{$\begin{array}{l}\text { Time dependent electric } \\
\text { fields are easily in- } \\
\text { cluded }\end{array}$} & \multicolumn{2}{|c|}{ Time dependent electric fields can be included } \\
\hline & \multicolumn{2}{|c|}{$\begin{array}{l}\text { Realistic band structure models can be fully } \\
\text { accounted }\end{array}$} \\
\hline
\end{tabular}

Table 2 : Possibilities of the various methods

\begin{tabular}{|l|c|l|}
\hline \multicolumn{1}{|c|}{ Balance equations } & \multicolumn{1}{|c|}{ Iterative technique } & Monte Carlo simulation \\
\hline $\begin{array}{l}\text { No rigorous justifica- } \\
\text { tion of the validity of } \\
\text { the equations can be } \\
\text { given }\end{array}$ & $\begin{array}{l}\text { The microscopic dynamics } \\
\text { of the scattering process } \\
\text { is somewhat hidden }\end{array}$ & $\begin{array}{l}\text { Details of the distri- } \\
\text { bution function are } \\
\text { not easily obtained }\end{array}$ \\
\hline $\begin{array}{l}\text { The stationary values } \\
\text { of the drift velocity, } \\
\text { of the mean energy and } \\
\text { of the effective mass } \\
\text { should be known a priori }\end{array}$ & $\begin{array}{l}\text { To fully exploit the potentiality of the method, } \\
\text { very fast computers are needed }\end{array}$ \\
\hline $\begin{array}{l}\text { Realistic band structu- } \\
\text { re models cannot be in- } \\
\text { cluded }\end{array}$ & & \\
\hline
\end{tabular}

Table 3 : Limitations of the methods

ACKNOWLEDGEMENTS : Part of the computer facilities have been kindly provided by the computer Center of the Modena University. 


\section{REFERENCES}

[1] H.F. BUDD, Proc. Int. Conf. Phys. Semicond., Kyoto, (1966), J. Phys. Soc. Japan, Suppl. 21, 420 (1966) and H.F. BUDD, Phys. Rev. 158, 798 (1967).

[2] T. KUROSAWA, Proc. Int. Conf. Phys. Semicond., Kyoto (1966), J. Phys. Soc. Japan. Suppl. 21, 424 (1966).

[3] H.D. REES, J. Phys. Chem. So]jds 30, 643 (1969)

[4] W. FAWCETT, A.D. BOARDMAN, S. SWAIN, J. Phys. Chem. Solids 31, 1963 (1970)

[5] G. BACCARANI, C. JACOBONI and A.M. MAZZONE, Solid St. Electron. 20, 5 (1977)

[6] P.A. LEBWOHL, J. App1. Phys. 44, 1744 (1973).

$[7]$ A. MATUlENENE, J. POZElA and $\bar{A}$. REKLAitis, Proc. $13^{\text {th }}$ Int. Conf. Phys. Semicond., Roma, 1235 (1976).

[8] D.K. FERRY, Phys. Lett. 78A, 375 (1980)

[9] D.K. FERRY and J.R. BARKER, Phys. Stat. SoT. (b) 100, 683 (1980)

[10] J.P. NOUGIER and M. ROLLAND, Phys. Rev. B8, 5728 (1973)

[11] J.P. NOUGIER, J.C. VAISSIERE, D. GASQUET, J. ZIMMERIIANN and E. CONSTANT, J. App T. Phys. 52, 825 (1981)

[12]. B. CARNEZ, A. CAPPI, A. KASZYNSKI, E. CONSTANT and G. SALMER, J. App 1. Phyś. 51, 786 (1980).

[13] L. REGGIANI, Proc. 15th Int. Conf. Physics of Semiconductors, Kyoto 1980, J. Phys. Soc. Japan 49, (1980) Suppl. A p. 317.

[14] F. NAVA, C. CANALI, L. REGGIANI, D. GASQUET, J.C. VAISSIERE and J.P.NOUGIER, J. App 7. Phys. 50, 922 (1979)

[15] G. OTTAVIANI, L. REgGiAnI, C. CANALI, F. NAVA and A. ALBERIGI-QuARANTA, Phys. Rev. 12B, 3318 (1975).

[16] L. REGGIANI, in Physics of non 1 inear transport in semiconductors, D.K. Ferry; R. Barker and C. Jacoboni ed., Plenum PubT. vol. 52, p. 467 (1980).

[17] This case can be of realistic importance for measurements with the time-offlight technique. 